\title{
. \\ NESTE ÅR I JERUSALEM \\ AMERIKANSK JERUSALEM-POLITIKK FRA TRUMAN TIL TRUMP (1947-2017)
}

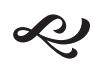

Amerikansk motvilje mot å flytte sin Israel-ambassade til Jerusalem gir inntrykk av en stabil amerikansk Jerusalem-politikk hvor us A står i opposisjon mot Israel. Ser man på amerikansk Jerusalem-politikk i et syttiårsperspektiv, blir det imidlertid klart at Israel gradvis har vunnet mot amerikansk ettergivenhet.

JØRGEN JENSEHAUGEN

DA PRESIDENT DONALD TRUMP I MAI 2017 BLE den første sittende amerikanske presidenten til å besøke klagemuren i Øst-Jerusalem, flyttet han usAs Jerusalem-politikk noen hakk i Israels favør. Det at han samtidig ga inntrykk av at usAs Jerusalem-politikk stod fast ved ikke å flytte den amerikanske ambassaden til Jerusalem, gjenspeiler de lange linjene i usAs Jerusalem-politikk. I det korte løp, er Jerusalem tilsynelatende den siste skanse hvor UsA står imot Israel. I et lengre perspektiv, derimot, har usA gradvis gitt etter for Israels krav. Denne artikkelen vil vise hvordan dette har skjedd ved å spore amerikansk Jerusalem-politikk fra det at Palestina-spørsmålet ble tatt opp i FN i 1947, under president Harry S. Truman, til det første halvåret under president Trump.

Jerusalem har siden opprinnelsen til den arabisk-israelske konflikten vært en av konfliktens kjernespørsmål grunnet byens enorme religiøse, så vel som nasjonalistiske, betydning for jøder og palestinere. Byen har også stor betydning i regionen, spesielt for stater som Jordan og Saudi-
Arabia. Sammen med flyktningspørsmålet er Jerusalem det vanskeligste og viktigste politiske temaet som partene strides om, og både israelerne og palestinerne ønsker seg byen som sin hovedstad.

I de første tiårene etter at $\mathrm{FN}$ involverte seg $\mathrm{i}$ konflikten, i 1947, krevde det internasjonale samfunnet at byen skulle være samlet under $\mathrm{FN}^{-}$ kontroll, corpus separatum-løsningen, eller svakere varianter av dette, som at kun gamlebyen skulle administreres som en samlet enhet. Etter krigen i 1967, da Israel okkuperte hele byen, har det eksistert primært to mulige løsninger: At byen deles mellom Israel og Jordan eller palestinerne; eller at byen forblir samlet, med sterk lokal autonomi, og at den fungerer som hovedstad for både Israel og Palestina. Tidsrammen for artikkelen deles derfor $\mathrm{i}$ to. I den første perioden (1947-1967) var byen delt, mens i den andre perioden (19672017) var byen samlet under israelsk okkupasjon. Dette skillet danner det analytiske bakteppet for utviklingen av amerikansk politikk. 


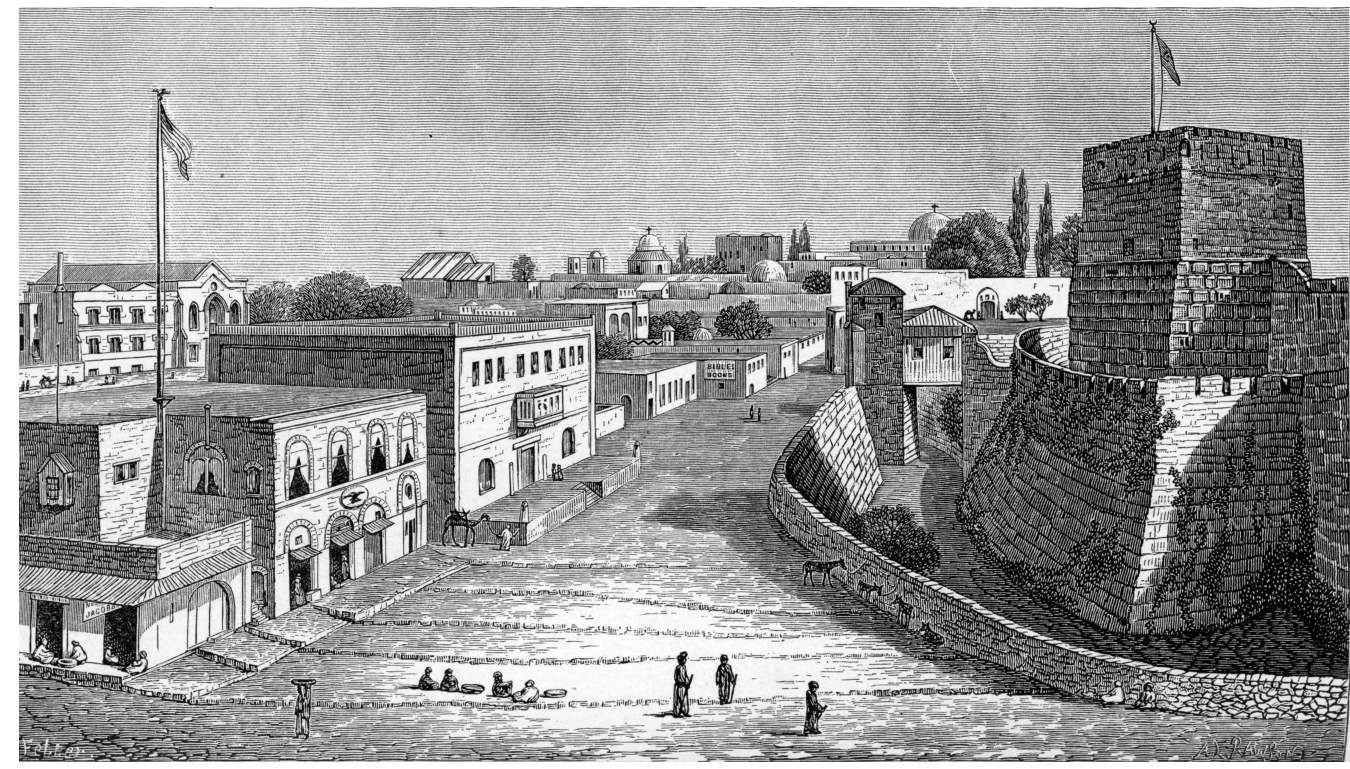

Det amerikanske konsulatet i Jerusalem anno 1857.

De lange linjene i usas Jerusalem-politikk er ikke tilstrekkelig studert. Det er hovedsakelig to hull i den eksisterende litteraturen. Det første er at det er få forskningsarbeider som trekker en lang sammenhengende tidslinje. Flere gode arbeider tar for seg usAs politikk i Jerusalem-spørsmålet i et konsentrert tidsrom, da primært i perioden før I967. ${ }^{1} \mathrm{Av}$ de som trekker lengre linjer stopper analysen som oftest ved George H.w. Bush, og i enkelte tilfeller ved Bill Clinton. ${ }^{2}$ Det finnes ikke noe fagarbeid som trekker linjene fram til Donald Trump.

Det andre hullet i den eksisterende litteraturen er at den generelt fokuserer på spesifikke aspekter, som ambassadespørsmålet og fredsforhandlinger. ${ }^{3}$ Ved å bruke en kombinasjon av arkivmateriale, publiserte kildesamlinger og sekundærlitteratur bidrar denne artikkelen til den eksisterende forskningen ved å trekke linjene fram til Trump, og ved å ta for seg en rekke arenaer hvor Jerusalem-spørsmålet har stått sentralt - FN, fredsforhandlinger og amerikansk innenrikspolitikk. Artikkelen viser at det er en tydelig tendens innenfor alle disse arenaene. Ved å stå steilt på sin posisjon, og ved å bruke støttespillere i amerikansk politikk, har Israel gradvis skiftet amerikansk politikk i deres favør. Skillelinjene i posisjonen fra én president til den neste er små, men i et syttiårsperspektiv er dagens amerikanske Jerusalem-politikk ugjenkjennelig fra den president Truman førte i I947. Noe av dette kan forklares med okkupasjonen som startet i 1967 , men trenden er den samme innad $\mathrm{i}$ de to tidsperiodene. Utviklingen fra Truman til Johnson og fra Johnson til Trump viser det samme: UsA har gradvis gitt etter for den israelske posisjonen.

\section{JERUSALEM SOM INTERNASJONAL BY, 1947-1967}

I fNs delingsplan fra november 1947 skulle Palestina deles $\mathrm{i}$ en jødisk stat, en arabisk stat, og Jerusalem-enklaven, som skulle være en FN-styrt corpus separatum. En modifisert utgave av dette ble presentert i Bernadotte-planen, september $1948 .^{4}$ Mellom disse to løsningsforslagene raste krigen i 
Palestina. Israel sikret seg den vestlige delen av byen, mens Jordan tok den østlige delen, inklusive gamlebyen. Delingen ble befestet ved våpenstillstandsavtalen mellom Israel og Jordan, signert 3. april I949. ${ }^{5}$

I denne perioden var USAs posisjon at Jerusalem skulle være en internasjonal by. ${ }^{6} \mathrm{I}$ juni I948 mente eksempelvis USAs utenriksminister George C. Marshall at Israel ikke hadde rett til å tale på vegne av Jerusalems jøder, siden byen ikke tilhørte Israel. ${ }^{7}$ Men amerikanerne tonet gradvis ned konseptet om Jerusalem som internasjonal by, siden de ikke var villige til å støtte en internasjonal militær tilstedeværelse for å sikre internasjonaliseringen. ${ }^{8}$ Spesielt etter våpenstillstandsavtalen ble usas standpunkt at internasjonalisering primært burde gjelde for de hellige stedene. ${ }^{9}$ I praksis var dette nærmere den israelske posisjonen, men prinsipielt hadde UsA og Israel

\section{De amerikanske diplomatene begynte å reise fra Tel Aviv til Jerusalem når de skulle møte den israelske regjeringen.}

motsatte posisjoner. UsA insisterte på at Jerusalem skulle internasjonaliseres, med lokal autonomi, mens Vest-Jerusalem ble integrert i Israel. Bak denne prinsipielle uenigheten, som kom til uttrykk i en rekke offentlige disputter, pekte interne diskusjoner på at UsA kunne akseptere delingen av byen så lenge dette var del av en fredsavtale mellom partene. ${ }^{10}$

I mellomtiden endret Israel og Jordan fakta på bakken, og piggtrådgjerder ble reist mellom de to delene av byen. I februar 1949 holdt Knesset sin første samling i Jerusalem, og i i949-1950 flyttet Israel regjeringskontorene og flesteparten av departementene sine fra Tel Aviv til Jerusalem. I
I950 ble Jerusalem proklamert som landets hovedstad. ${ }^{11}$ usA reagerte med å forby sine diplomater å utføre oppgaver i Jerusalem, og president Truman nektet usAs ambassadør å delta på åpningen av Knesset i i949. Washington ville ikke signalisere at man aksepterte Israels kontroll over byen, mens Israel motsatte seg usAs politikk ved å insistere på at alle møter måtte foregå i Jerusalem. Denne isfronten kunne ikke vare siden det i praksis umuliggjorde de amerikanske diplomatenes arbeid. I februar I95 I ga USA seg, og de amerikanske diplomatene begynte å reise fra Tel Aviv til Jerusalem når de skulle møte den israelske regjeringen. ${ }^{12}$ Dette var det første store signalet om at UsA gradvis kom til å gi etter for Israels posisjon.

Prinsipielt var de to landene uenige. Da Israel i 1953 utfordret verdenssamfunnets posisjon på Jerusalem ved å flytte utenriksdepartementet til byen, gjeninførte usA sin politikk om ikke å møte den israelske regjeringen i Jerusalem. ${ }^{13}$ Formelt stod USA hardt på posisjonen sin i denne perioden. En av forklaringene er at president Dwight D. Eisenhower ønsket å føre en balansert Midtøstenpolitikk og igangsette en fredsprosess. Ettergivenhet overfor Israel i Jerusalem-spørsmålet ville vært svært skadelig $i$ et slikt henseende. Israel ble overasket over hvor hardnakket usA stod på sin politikk. ${ }^{14}$ UsA stod nemlig i fremste rekke i å opprettholde denne posisjonen i det internasjonale samfunnet ved å jobbe mot at andre land skulle flytte ambassadene sine til Jerusalem. Dette lyktes de i stor grad med. ${ }^{15}$

Israel satte hardt mot hardt, og vant flere gradvise politiske seire mot usA. Da Israel krevde at nye ambassadører måtte presentere kreditivene sine i Jerusalem protesterte USA, men ga seg da de byttet ambassadør i november $1954 .{ }^{16}$ Innen 1959 hadde Israel sikret seg at ingen stater insisterte på at møter måtte foregå i Tel Aviv. Det samme året lovet UsA, i en hemmelig avtale, at landet ikke 
lenger skulle motarbeide at andre stater flyttet ambassadene sine. ${ }^{17}$

I I962 var israelerne tilstrekkelig sikre på at de hadde knekt boikotten mot å møte dem i Jerusalem og stengte derfor utenriksdepartementets møtekontor i Tel Aviv. Washington protesterte, men aksepterte situasjonen. ${ }^{18}$ Eisenhower, og hans ønske om å føre en «balansert» Midtøsten-politikk, ble i I96I erstattet av John F. Kennedy og det han kalte et «special relationship» med Israel. ${ }^{19}$ Forholdet mellom usa og Israel ble tettere, og da President Lyndon B. Johnson tok over etter drapet på Kennedy i I963, informerte han Israel: «You have lost a great friend, but you have found a better one.» ${ }^{20}$

Merkverdig nok medførte ikke denne pro-israelske vendingen $\mathrm{i}$ USA at standpunktet til Jerusalem ble endret umiddelbart. Da Israel åpnet det nye Knesset i Jerusalem i i966, var ingen amerikanske diplomater til stede, som i i949. Det var derimot flere medlemmer av den amerikanske Kongressen. ${ }^{21}$ Dette viste en av de store og vedvarende spenningene i amerikansk Jerusalempolitikk: Som utenrikspolitisk tema kan usA stå mot Israels posisjon, men innenrikspolitisk har USA støttet Israels posisjon. Det er denne mekanismen som gjør at Jerusalem ofte ser helt annerledes ut i amerikansk valgkamp enn den gjør i Det hvite hus. Dette er en av de meste sentrale spenningen for å forstå utviklingen av amerikansk Jerusalem-politikk. Denne spenningen blir stadig mer sentral jo nærmere vi kommer samtiden.

USAs reaksjon på åpningen av Knesset i 1966 utgjorde unntaket i en utvikling i perioden før krigen i i967. Det eneste som i realiteten stod fast på amerikansk side i perioden I947-I967 var at man ikke anerkjente at Israel hadde suverenitet i Jerusalem. Samtidig befestet Israel og Jordan sin kontroll over byen, og det ble stadig vanskeligere å reversere situasjonen. I faglitteraturen er det to komplementerende forklaringer på dette. Elad
Ben-Dror og Asaf Ziedler viser hvordan Israel og Jordan hadde felles interesse $\mathrm{i}$ å hindre internasjonalisering. ${ }^{22}$ Dette betydde at usa ikke hadde en part på bakken som støttet amerikansk politikk. Den andre forklaringen er at UsA gradvis brydde seg mindre om Jerusalem, som historiker Peter L. Hahn kommenterte: «By remaining passive, us officials allowed the question of Jerusalem to recede from view as Israel wished.» ${ }^{23}$

\section{7 - ISRAEL EROBRER ØST-JERUSALEM}

Da Israel erobret Øst-Jerusalem den 7. juni I967, uttalte forsvarsminister Moshe Dayan at byen var "gjenforent» og at Israel aldri kom til å forlate den. ${ }^{24}$ Israel visste at dette ville vekke reaksjoner siden det internasjonale samfunnet også da anså Jerusalem som et av konfliktens mest betente politiske temaer. Da Israel annekterte Øst-Jerusalem i I 967, kommenterte israelske diplomater i interne dokumenter: «Dette vil kreve hasbara [propaganda]». ${ }^{25}$ Et av grepene var å pakke annekteringen inn som en administrativ «fusjon». ${ }^{26}$ Israels okkupasjon av hele byen endret den politiske situasjonen totalt.

Da usAs president Lyndon B. Johnson talte om konflikten etter seksdagerskrigen var ikke lenger internasjonalisering av Jerusalem på agendaen. Det eneste som gjenstod av internasjonaliseringspolitikken var kravet om at de hellige stedene for de tre religionene måtte beskyttes. ${ }^{27}$ UsAs posisjon havnet dermed et hakk nærmere den israelske ved at man aksepterte Vest-Jerusalem som israelsk. Dette innebar en retroaktiv anerkjennelse av det som hadde skjedd med Jerusalem i I947-1949krigen, men en motstand mot det som hadde skjedd i r967-krigen. Dette gjenspeilet utviklingen $\mathrm{i}$ synet på konflikten for øvrig. FNs resolusjon 242, vedtatt 22. november I967 av FNS sikkerhetsråd, krevde kun at Israel skulle trekke seg ut av territorier okkupert i den siste krigen. ${ }^{28}$

Resolusjon 242 nevnte ikke Jerusalem med ett 
ord. De britiske diplomatene som utformet resolusjonen var mer kritisk til Israels okkupasjon av Øst-Jerusalem enn amerikanerne, men de aksepterte at en resolusjon som refererte til Jerusalem ikke ville få støtte. ${ }^{29}$ Israel brukte de første månedene etter krigen til å endre fakta på bakken i Jerusalem. De fjernet hindringene som delte byen, koblet sammen infrastrukturen mellom byens to deler og fjernet palestinsk bebyggelse fra den jødiske delen av gamlebyen. Ingen sikkerhetsrådsresolusjon kritiserte eksplisitt Israel for dette. Først i mai 1968, og etter nesten et år med store endringer på bakken, fordømte FNs sikkerhetsråd Israels okkupasjon av Jerusalem i resolusjon $252 .{ }^{30}$ usA lot resolusjonen gå gjennom ved å avstå fra å stemme. ${ }^{31}$

Nixon-administrasjonen, som overtok i I969, var i utgangspunktet strengere mot Israel enn Johnson hadde vært. I juli I969 stemte usa for sikkerhetsrådsresolusjon 267 som fordømte Israels Jerusalem-politikk. ${ }^{32}$ I sin tale til FN gjorde UsAs FN-ambassadør Charles Yost det tydelig at UsA anså Israel som en okkupasjonsmakt i ØstJerusalem. ${ }^{33}$ Denne posisjonen ble bekreftet da USA stemte for resolusjon 298 i september I97I. Resolusjonen fordømte Israels okkupasjonspolitikk i Øst-Jerusalem. ${ }^{34}$

Fem år senere, under president Gerald Ford, i mars 1976, nedla amerikanerne veto mot en lignende resolusjon selv om de hadde poengtert at de stod bak innholdet i den. ${ }^{35}$ Dynamikken var åpenbar. I I 969 hadde Nixon-administrasjonen stemt for en resolusjon som fordømte Israels Jerusalem-politikk fordi dette var et nødvendig ledd i lanseringen av Rogers-planen, Nixon-administrasjonens forsøk på en fredsløsning i Midtøsten. Denne feilet, og i 1976 fikk innenrikspolitiske forhold i usA forrang. Da nedla usA veto fordi det var valgkamp og kritikk av Israel var upopulært i usA. Etter at Ford tapte valgkampen mot Jimmy Carter, støttet Ford derimot en uttal- else fra Sikkerhetsrådet som fordømte Israels Jerusalem-politikk. ${ }^{36}$ Som vi skal se har USA dempet sin kritikk av Israels okkupasjon av ØstJerusalem i FN, delvis som et resultat av usAs økende engasjement i diverse fredsprosesser.

\section{JERUSALEM DRUKNER I FREDSPROSESSEN}

President Carter støttet innholdet i de tydelige FN-resolusjonene som fordømte Israels okkupasjonspolitikk, men han ville ikke stemme for resolusjoner i FN som tilkjennega denne posisjonen. ${ }^{37}$ Dette kan forklares med de daværende fredsforhandlingene. Israels statsminister, Menachem Begin, stod hardnakket på alle Israels krav på Jerusalem, og han var villig til å kansellere all diplomatisk fremgang hvis han anså Israels kontroll over Jerusalem som svekket.

Eksempelvis oppstod det en Jerusalem-krise på den siste dagen av Camp David-forhandlingene i 1978. Begin nektet å akseptere at det $\mathrm{i}$ et av anneksene til avtalen stod at USA anså ØstJerusalem som okkupert. Da Begin truet med å

\section{President Carter støttet innholdet i de} tydelige FN-resolusjonene som fordømte Israels okkupasjonspolitikk.

forlate Camp David uten en avtale, fjernet Carter formuleringen og erstattet den med referanser til tidligere amerikanske uttalelser i FN. Disse uttalelsene hadde karakterisert Øst-Jerusalem som okkupert. En referanse til slike uttalelser i FN er langt mindre politisk tungtveiende enn en avtaletekst som eksplisitt hevder at Øst-Jerusalem er okkupert. Ved å fjerne Jerusalem fra Camp David ga Carter Israel det de ville ha, selv om han mente det motsatte. ${ }^{38}$

Det mest merkverdige eksempelet på Carters tvetydige posisjon på Jerusalem kom da Sikker- 
hetsrådet vedtok resolusjon $465 \mathrm{i}$ mars I980. Resolusjonen fordømte Israels bosettingspolitikk på de okkuperte områdene, inklusive Jerusalem. ${ }^{39}$ UsA stemte først for resolusjonen, men da Carter oppdaget at den inneholdt en formulering om Jerusalem trakk han usAs støtte. ${ }^{40}$ Mot slutten av presidentperioden ble Carter igjen sterkt utfordret av Begin, da Knesset vedtok Jerusalem-loven i I980. Loven erklærte at Jerusalem, i sin helhet, var Israels hovedstad. ${ }^{41}$ Dette var en sementering av politikken Israel hadde ført siden juni i967. Carter ble dypt forarget, siden loven torpederte siste rest av forhandlingsvilje på arabisk side. Likevel, da FNs sikkerhetsråd vedtok resolusjon 478 som fordømte loven, avstod usA fra å stemme. ${ }^{42}$ Dette understreket den tydelige tendensen under Carter. Han insisterte både på at Øst-Jerusalem var okkupert av Israel og at usA ikke skulle agere mot Israel i FN.

\section{JERUSALEM I FN ETTER 1967}

Carters utenriksminister Cyrus Vance uttalte at usAs Jerusalem-politikk hadde vært den samme under de fire siste presidentene, det vil si Johnson, Nixon, Ford og Carter. ${ }^{43}$ Dette var en sannhet med modifikasjoner. Tvetydigheten i Carters Jerusalem-politikk reflekterte den generelle utviklingen i amerikansk Jerusalem-politikk i FN. Ser vi på oversikten over hvordan UsA har stemt på resolusjoner i FNs sikkerhetsråd etter krigen i 1967, som enten fordømmer israelske handlinger i Jerusalem, eller som eksplisitt hevder at ØstJerusalem er okkupert, oppdager vi tydelige mønstre (se appendiks). Det første er at Jerusalem var mest aktivt stemt over i perioden $1977^{-200 I . ~}$ Under presidentperiodene til Carter, Reagan, Bush og Clinton var Jerusalem tema i totalt 36 avstemninger. I perioden I967-I977 var det tema syv ganger, og i perioden 200I-20I7 var det tema ved kun seks avstemninger. Den andre trenden er at med unntak av ett tilfelle under Ford og ett under
Carter, så stemte ikke usA mot slike resolusjoner før under president Ronald Reagan. Han stemte mot hele syv slike resolusjoner. Deretter stemte Bush mot fire, Clinton mot tre, Bush mot fire og Obama mot én.

Den tredje trenden er at USA gradvis sluttet å stemme for slike resolusjoner. Både Johnson og Nixon, ansett som nære allierte av Israel, stemte for to slike resolusjoner hver. Carter stemte for én slik resolusjon, men trakk dette tilbake. Reagan stemte også for én slik resolusjon. President George H.w. Bush utmerker seg som unntaket i det generelle mønsteret. Han stemte for seks slike resolusjoner. Bill Clinton var tilsynelatende den siste amerikanske presidenten til å stemme for en slik resolusjon i Sikkerhetsrådet, men djevelen ligger i detaljene. Da Sikkerhetsrådet fordømte Hebron-massakren i 1994, i resolusjon 904, stemte USA for mesteparten av resolusjonen, men avstod fra å stemme over det avsnittet som beskrev Øst-Jerusalem som okkupert. ${ }^{44}$ Dette betyr at USA ikke har fordømt Israels Jerusalem-politikk i Sikkerhetsrådet etter desember 1992. Mens George H.w. Bush var den siste amerikanske presidenten som stemte for slike resolusjoner, utmerket hans sønn, George W. Bush, seg med sitt eksklusive bruk av veto for å beskytte Israel mot kritikk i Sikkerhetsrådet.

Et av argumentene UsA har brukt for ikke å stemme for resolusjoner som omhandler Jerusalem, er at Jerusalem er tema for fredsforhandlinger, og at $\mathrm{FN}$ derfor ikke skal påvirke Jerusalems status før forhandlingene er avsluttet. ${ }^{45}$ I praksis betyr dette at palestinernes krav på $Ø$ stJerusalem holdes gissel av en stadig mer fastlåst fredsprosess. Dette er motsatsen til den posisjonen presidentene Johnson og Nixon tok, nemlig at å støtte Israel i Jerusalem vil hindre utviklingen av en fredsprosess.

Denne oversikten gir ikke det fulle bildet. Det er spesielt tre forbehold som må tas. For det første 
handler mange av resolusjonene om andre ting enn Jerusalem, men inneholder formuleringen «inkludert Jerusalem» i de okkuperte områdene. For det andre inkluderes ikke resolusjoner som omtaler de okkuperte områdene generelt, men som ikke spesifiserer Jerusalem. For det tredje avtar antallet resolusjonsforslag fordi det etter hvert forventes at usA kommer til å nedlegge veto. Dette var resultatet av en gradvis utvikling. I I970 hadde Israels statsminister Golda Meir bedt om et løfte fra USA om at amerikanerne skulle legge ned veto mot resolusjoner som fordømte Israel. Nixon-administrasjonen svarte ikke på henvendelsen. ${ }^{46}$ Fra og med 1973 ble derimot bruken av veto for å beskytte Israel i Sikkerhetsrådet en tradisjon. ${ }^{47}$ Så, i I991, ble Israel betrygget om at UsA ville nedlegge veto mot resolusjoner som fordømte Israel. ${ }^{48}$ Fra midten av I990-årene ble veto langt sjeldnere brukt i Sikkerhetsrådet fordi avstemninger som forventes å resultere i vetobruk ikke stemmes over. ${ }^{49}$

Et tydelig eksempel på hvordan resolusjoner som forventes å bli nedstemt ikke blir stemt over skjedde under Carter, da PLO og Kuwait sommeren 1979 samarbeidet om en resolusjon som skulle erstatte resolusjon 242 og anerkjenne palestinsk selvbestemmelsesrett. Da det ble klart at USA kom til å stemme imot uansett hvor mye PLO modererte resolusjonen, ble den ikke fremmet. ${ }^{50}$ Antallet «mot»-stemmer har altså minket ettersom det har blitt tydelig at usA kom til å stemme mot omtrent alle Israel-kritiske resolusjoner. FNs sikkerhetsråd har derfor blitt en langt mindre viktig arena for å forstå utviklingen i usAs Jerusalem-politikk.

\section{JERUSALEM I AMERIKANSK VALGKAMP}

Fra og med president Ronald Reagan ble spriket mellom Jerusalem som tema i valgkampen og i utenrikspolitikken veldig tydelig. Som presidentkandidat, i mars I980, støttet Reagan Israels krav på suverenitet over hele Jerusalem. Da han to år senere, i september 1982, lanserte sin fredsplan var Jerusalem noe partene måtte bli enige om, og i februar I983 uttalte utenriksminister George P. Shultz at administrasjonen anså Øst-Jerusalem som okkupert territorium. ${ }^{51}$

Presidenten og utenriksdepartementet hadde ikke monopol på Jerusalem-spørsmålet, selv om det var et utenrikspolitisk spørsmål. En sterk symbolsak kom til å illustrere dette. Fra tidlig på I980-tallet begynte en dragkamp mellom Israels sterkeste støttespillere i Kongressen og Det hvite hus om beliggenheten til den amerikanske ambassaden i Israel. Mens Kongressen begynte å støtte at ambassaden burde flyttes til Jerusalem, har Det hvite hus og utenriksdepartementet stått på sin posisjon om at ambassaden skal forbli i Tel Aviv. I I983 nedstemte Kongressen et forslag om

\section{$\partial$ \\ President George H.w. Bush utmerker seg som unntaket i det generelle mønsteret.}

flytting av ambassaden, men i I984 vedtok Kongressen en ikke-bindende resolusjon om at ambassaden burde flyttes snarest mulig. ${ }^{52}$ Allerede fra 1984 ble dette del av partiplattformen til Demokratene, og med unntak av valgkampen i 2OI2, da formuleringen om Jerusalem som Israels udelte hovedstad opprinnelig ble fjernet (men så gjeninnsatt) har det vært lite debatt omkring Jerusalem-spørsmålet i de to partiene. ${ }^{53}$

I 1988 vedtok Kongressen «Helms-tillegget» som åpnet for at UsA kunne bygge diplomatiske fasiliteter i både Tel Aviv og Jerusalem. ${ }^{54}$ Etter dette vedtaket signerte president Ronald Reagan en leiekontrakt på 99 år for en tomt i Jerusalem tiltenkt ambassaden. ${ }^{55}$ Ikke bare signaliserte dette en dreining mot å anerkjenne Jerusalem som Is- 
raels hovedstad, men en gruppe forskere avslørte at mesteparten av tomten tilhørte en gruppe palestinske flyktninger. ${ }^{56}$ Dette sammenfalt i tid med at Jordan sa fra seg sitt krav på Vestbredden, noe som betydde at i fremtidige forhandlinger ville Jerusalem være en sak som primært angikk Israel og palestinerne.

Siden 1984 har ambassadespørsmålet preget presidentvalgkampen, og i 1992 ble Bill Clinton den første amerikanske presidenten som i valgkampen lovet å flytte ambassaden til Jerusalem. ${ }^{57}$ Han kritiserte sin motkandidat, president George H.w. Bush, for å ikke anerkjenne israelsk suverenitet over hele byen. ${ }^{58}$ Dette var det klassiske eksempelet på forskjellen Jerusalem spiller i amerikansk valgkamp og $\mathrm{i}$ det amerikanske presidentembetet. Clinton, som Bush før ham, gjorde ingenting for å endre Jerusalems status da han entret Det hvite hus. Det som var populær innenrikspolitikk i valgkampen ble umiddelbart ansett som noe som kunne torpedere en gryende fredsprosess. ${ }^{59}$

Paradokset med dette standpunktet er at Jerusalem - som er et av de vanskeligste spørsmålene i konflikten - i realiteten sjelden var et tema $\mathrm{i}$ forhandlingene, fordi det regnes som et sluttstatusspørsmål. Jerusalem har derfor ofte blitt et utsatt tema $\mathrm{i}$ forhandlingene. $\mathrm{Vi}$ har allerede sett hvordan dette foregikk i Camp Davidforhandlingene, men også i Oslo-forhandlingene, som usA riktignok ikke var del av, klarte Israel å utsette Jerusalem-spørsmålet. ${ }^{60}$ Det mønsteret fortsatte $\mathrm{i}$ årene som fulgte. I realiteten var Jerusalem kun tema i forhandlingene mot slutten av Bill Clintons presidentperiode, mellom juli 2000 og januar 200I, og sent i Bush-perioden, $2007^{-2008} .^{61}$

Samtidig som amerikanske presidenter insisterte på at Jerusalems status kun kan avgjøres ved forhandlinger mellom partene, har Israels støttespillere i Kongressen jobbet for at usA skal aner- kjenne hele byen som Israels hovedstad. Det tydeligste eksempelet på dette er «Jerusalem embassy act» fra I995, som ble støttet av Israellobbyens hovedorgan, AIPAC, men motarbeidet av president Clinton. Loven krevde at presidenten skal flytte ambassaden til Jerusalem, men den inneholdt en klausul om at den amerikanske presidenten kan undertegne en seks måneder lang utsettelse av flyttingen hvis han anser flyttingen som en fare for rikets sikkerhet. ${ }^{62}$ Mønsteret fra Clintons første valg har gjentatt seg ved at presidentkandidater har støttet flyttingen, mens sittende presidenter har motsatt seg det. Eksempler på presidentkandidater som har lovet å flytte ambassaden inkluderer republikanerne George W. Bush, John McCain og Mitt Romney, og demokratene Bill Clinton, Al Gore og Hillary Clinton. ${ }^{63}$ Amerikanske presidenter har signert utsettelsespapirene hver sjette måned siden 1995 . President Trump var den seneste til å gjøre det. ${ }^{64}$

Enn så lenge har usA avstått fra å utstede en $d e$ jure anerkjennelse av Jerusalem som Israels hovedstad, selv om de de facto anerkjenner VestJerusalem som Israels hovedstad. us As offisielle posisjon er fortsatt at en de jure anerkjennelse kun kan komme etter en endelig fredsavtale mellom Israel og palestinerne. ${ }^{65}$ Selv om en slik løsning er opp til partene, så regnes de såkalte Clintonparameterne som sentrale. Ifølge disse skal byen deles slik at de palestinske bydelene tilfaller palestinerne, mens de jødiske bydelene tilfaller Israel. ${ }^{66}$ Disse parameterne fulgte president Bush inn i Det hvite hus, men med den andre intifadaen (som startet i Jerusalem i september 2000), fraværet av en fungerende fredsprosess før mot slutten, og ingen Israel-kritiske resolusjoner i Sikkerhetsrådet, befestet Israel sin kontroll over byen.

\section{BARACK OBAMA}

Barack Obama er et unntak i de siste tre tiårenes amerikanske valgkampshistorie. Han krevde ikke 
at ambassaden skulle flyttes, selv om han beskrev Jerusalem som «Israels udelte hovedstad». ${ }^{67}$ Få forventet derfor at Obama skulle flytte ambassaden. Men ambassadeflyttingen var ikke den eneste kampen Obama fikk ta mot Israels sterkeste støttespillere. President Obama stanset en lovendring som ville medført at amerikanske barn født i Jerusalem fikk «Israel» som fødested i passene sine. ${ }^{68}$ Obama-administrasjonen hevdet at amerikansk politikk hadde stått fast siden president Truman: «to recognize no state as having sovereignty over Jerusalem, leaving the issue

\section{$\infty$ \\ President Obama var et slående eksempel på hvordan usA har feilet i Jerusalem.}

to be decided by negotiations between the parties». ${ }^{69}$ Som vi har sett er dette en sterk overdrivelse. Amerikansk Jerusalem-politikk hadde endret seg drastisk siden Truman støttet corpus separatum-løsningen.

I FN avsluttet Obama presidentperioden sin med å tillate at sikkerhetsrådsresolusjon 2334 gikk gjennom ved at usA avstod fra å stemme. Resolusjonen inkluderte Øst-Jerusalem som del av de okkuperte territoriene. ${ }^{70}$ Det var første gang siden oktober 2000 at UsA hadde avstått fra å stemme over en slik resolusjon i Sikkerhetsrådet.

Selv om Obama ikke aksepterte Israels krav på hele Jerusalem, var hans Jerusalem-politikk vag. I Obamas berømte Kairo-tale i 2009, ble Jerusalem kun nevnt én gang, og da i svært utopiske ordelag. ${ }^{71}$ Obama presset på for en bosettingsstans, inkludert i Øst-Jerusalem, men ga seg da Israels statsminister insisterte på at en slik midlertidig stans ikke kunne gjelde Øst-Jerusalem. ${ }^{72}$ Også under forhandlingene ledet av utenriks- minister John Kerry ble Jerusalem kun vagt adressert. ${ }^{73}$ Illustrerende for hvordan Obama ga etter for Israels posisjon på Jerusalem er spesialutsending George Mitchell sitt svar da palestinernes sjefsforhandler Saeb Erekat ba om amerikansk hjelp til bosettingsstans i Jerusalem: «there is no way, even if we engage with the Israelis till doomsday». ${ }^{74}$

President Obama var et slående eksempel på hvordan usa har feilet i Jerusalem. Siden Israel okkuperte Øst-Jerusalem i I967 har 210 ooo bosettere flyttet inn i den okkuperte delen av byen. ${ }^{75}$ Selv om slike bosettinger er noen av de mest problematiske av alle bosettinger så har amerikanske administrasjoner, spesielt siden Clinton, vært mindre kritiske mot disse utbyggingene. ${ }^{76}$ Israel har styrket sin kontroll over Øst-Jerusalem for hvert år, mens usAs kritikk har minket. Istedenfor å kritisere Israel i FN eller koble bistand til bosettingene, slik George H.w. Bush gjorde før Madrid-konferansen, ${ }^{77}$ stod UsA igjen med symbolsaker som motstand mot ambassadeflyttingen og formaliteter i passene som en siste skanse.

\section{FRA DAG EN TIL SEKS MÅNEDERS UTSETTELSE}

Debatten om ambassadeflytting fikk nytt liv under valgkampen til Donald Trump og perioden etterpå. Ikke bare lovet han å flytte ambassaden i de vanlige arenaene, slik som på AIPAC-møter, men det ble også frontet som en sak med høy prioritet. ${ }^{78}$ Donald Trump er en uvanlig president, og mange fryktet at den vanlige regelen om at ambassadeflyttingen kun var et valgkampslagord ikke kom til å gjelde. En grunn til en slik bekymring var at Trump-teamet frontet ambassadeflyttingen aktivt, men unnlot å diskutere temaet med det amerikanske utenriksdepartementet. ${ }^{79}$ Utenriksdepartementet er blant de grenene i den amerikanske administrasjonen som sterkest har motsatt seg ambassadeflyttingen. ${ }^{80}$ 


\section{APPENDIKS}

Oversikt over hvordan USA har stemt i FNs sikkerhetsrå til resolusjonsforslag som enten fordømmer israelske handlinger i Jerusalem eller eksplisitt betegner Jerusalem som okkupert territorium, 1967-2017.

\section{Lyndon B. Johnson 1967-1969}

$\mathbf{1}$ avsto, $\mathbf{2}$ for.

Resolusjon 250, 27. april 1968: USA for.

Resolusjon 251, 2. mai 1968: USA for.

Resolusjon 252, 21. mai 1968: USA avsto.

\section{Richard Nixon 1969-1974}

$\mathbf{1}$ avsto, $\mathbf{2}$ for.

Resolusjon 267, 3. juli 1969: USA for.

Resolusjon 271, 15. september 1969: USA avsto.

Resolusjon 298, 25. september 1971: USA for.

\section{Gerald Ford 1974-1977}

1 mot.

S/12022, 24. mars 1976: USA mot.

\section{Jimmy Carter 1977-1981}

1 mot, 5 avsto, 1 for endret til avsto.

Resolusjon 446, 22. mars 1979: USA avsto.

Resolusjon 452, 20. juli 1979: USA avsto.

Resolusjon 465, 1. mars 1980: USA for (Carter trakk senere støtten til resolusjonen).

S/13911, 28. april 1980: USA mot.

Resolusjon 471, 5. juni 1980: USA avsto.

Resolusjon 476, 30. juni 1980: USA avsto.

Resolusjon 478, 20. august 1980: USA avsto.

\section{Ronald Reagan 1981-1989}

$\mathbf{7}$ mot, $\mathbf{3}$ avsto, $\mathbf{1}$ for.

S/14943, 1. april 1982: USA mot.

S/14985, 20. april 1982: USA mot.

S/15895, 1. august 1983: USA mot.

S/17459, 12. september 1985: USA mot

S/17769, 29. januar 1986: USA mot

Resolusjon 592, 8. desember 1986: USA avsto.

Resolusjon 605, 22. desember 1987: USA avsto.

Resolusjon 607, 5. januar 1988: USA for.

Resolusjon 608, 14. januar 1988: USA avsto.

S/19466, 29. januar 1988: USA mot.

S/19780, 14. april 1988: USA mot.

\section{George H.W. Bush 1989-1993}

4 mot, 2 avsto, 6 for.

S/20463, 17. februar 1989: USA mot

S/20677, 8. juni 1989: USA mot

Resolusjon 636, 6. juli 1989: USA avsto.

Resolusjon 641, 30. august 1989: USA avsto.

S/20945/Rev. 1, 6. november 1989: USA mot.

S/21326, 30. mai 1990: USA mot.

Resolusjon 672, 12. oktober 1990: USA for.

Resolusjon 673, 24. oktober 1990: USA for.

Resolusjon 681, 20. desember 1990: USA for.

Resolusjon 694, 24. mai 1991: USA for.

Resolusjon 726, 6. januar 1992: USA for.

Resolusjon 799, 18. desember 1992: USA for.

\section{Bill Clinton 1993-2001}

$\mathbf{3}$ mot, $\mathbf{2}$ avsto, $\mathbf{1}$ avsto delvis.

Resolusjon 904, 18. mars 1994: USA avsto delvis.

S/1995/394, 17. mai 1995: USA mot.

Resolusjon 1073, 28. september 1996: USA avsto.

S/1997/199, 7. mars 1997: USA mot.

S/1997/241, 21. mars 1997: USA mot.

Resolusjon 1322, 7. oktober 2000: USA avsto.

\section{George W. Bush 2001-2009 \\ 4 mot. \\ S/2001/1270, 26. mars 2001: USA mot. \\ $\mathrm{S} / 2001 / 1199,14$. desember 2001: USA mot. \\ S/2004/240, 24. mars 2004: USA mot. \\ S/2006/878, 10. november 2006: USA mot.}

\section{Barack Obama 2009-2017}

1 mot, 1 avsto.

S/2011/124, 18. februar 2011: USA mot.

Resolusjon 2334, 23. desember 2016: USA avsto.

\footnotetext{
Per president: mot - avsto - for

Johnson: 0-1-2 (2 åx- 3 avstemninger)

Nixon: 0-1-2 (5 år - 3 avstemninger)

Ford: 1-0-0 (3 år - 1 avstemning)

Carter: 1-5(6)-1(0) (4 åख- 7 avstemninger)

Reagan: 7-3-1 (8 år - 11 avstemninger)

Bush: 4-2-6 (4 åx- 12 avstemninger)

Clinton: 3-2(3)-1(0) (8 år - 6 avstemninger)

Bush: 4-0-0 (8 år - 4 avstemninger)

Obama: 1-1-0 (8 år - 2 avstemninger)
} 
Frykten for at Trump mente alvor ble tydelig illustrert av de forskjellige truslene som kom fra palestinsk hold. Sjefsforhandler Saeb Erekat erklærte at hvis ambassaden ble flyttet så ville det bety fredsprosessens $\mathrm{d} \varnothing \mathrm{d}$, at kaos ville bryte ut $\mathrm{i}$ regionen, at sikkerhetssamarbeidet med Israel ville brytes og at palestinerne ville oppfordre andre arabiske land til å utvise sine amerikanske ambassadører. ${ }^{81}$ Selv om den formelle grunnen til å ikke flytte ambassaden er at en anerkjennelse av Israels kontroll over hele byen vil være nådestøtet for fredsprosessen, så er den regionale koblingen særdeles viktig, og forklarer i stor grad hvorfor amerikanerne ikke flytter ambassaden. Spesielt for Jordan og Saudi-Arabia, som er usAs allierte, er Jerusalem ekstremt viktig, og en ambassadeflytting vil skade usAs forhold til de arabiske landene. Jerusalem er ikke en sak som bare angår Israel og palestinerne, men det er en sak som er langt større enn seg selv.

Siden Obama signerte den siste seksmånedersutsettelsen rett før han gikk av, hadde Trump et halvt år på å bestemme seg for hva han ville gjøre. Det var uklart hva Trump ville gjøre før utenriksminister Rex Tillerson, den I4. mai 20I7, uttalte at spørsmålet måtte ses i sammenheng med fredsprosessen. ${ }^{82}$ I det diplomatiske kodespråket betydde dette at de ikke ville flytte ambassaden. Trump flyttet likevel grensen i usas Jerusalempolitikk da han ble den første sittende amerikanske presidenten til å besøke klagemuren i Øst-Jerusalem. ${ }^{83}$ Samtidig uttalte utenriksminister Rex Tillerson og den nasjonale sikkerhetsrådgiveren H. R. McMaster at klagemuren ligger i Jerusalem, altså ikke i Israel. ${ }^{84}$

\section{KONKLUSJON}

Obama og Trump står sammen som talende eksempler på hvordan usAs posisjon til Jerusalem gradvis har blitt utvannet og nærmet seg den israelske posisjonen. Under Obama var ikke ambas- sadeflyttingen noe stort tema og han bekjempet at Jerusalem skulle regnes som Israel i amerikanske pass. Han mente også at bosettinger i Jerusalem var «hindre» for fred, men gjorde lite for å stanse utbyggingen av disse. ${ }^{85}$ Formelt sett er Trump sin posisjon den samme, men ambassadeflyttingen har blitt et stort tema og han har gitt symbolsk (men ikke formell) støtte til at klagemuren er del av Israel. Han har også nedtonet kritikken av bosettinger fra «hindre» til «ikke-hjelpsomme». ${ }^{86}$ Begge disse begrepene er sterke nedtoninger av det tidligere presidenter har brukt. George H.w. Bush betegnet bosettingene som «ulovlige». ${ }^{87}$

Det er to elementer som forklarer denne sytti år lange utviklingen hvor usA gradvis har gitt etter for Israel. Det første er at Jerusalem er et langt viktigere spørsmål for Israel enn det er for UsA. Dette betyr at Israel har kunnet jobbe systematisk og målrettet for å endre byens status, mens usA har vært opptatt med en lang rekke andre utenrikspolitiske spørsmål. Den andre forklaringsfaktoren er at det eksisterer en intern amerikansk spenning mellom Jerusalem som utenrikspolitisk tema og Jerusalem som innenrikspolitisk tema. I den innenrikspolitiske debatten har Israel sterke støttespillere, som AIPAC. Kombinasjonen av disse to elementene svekker usAs posisjon og styrker Israels, siden Israel kan presse usA på to fronter.

Dette er noe Israel har dratt sterk nytte av over tid. Dette kan illustreres med at samtidig som det er milevis mellom Truman og Trump sin Jerusalem-politikk, er det lite som skiller Truman og Eisenhower, eller Obama og Trump, i deres politikk overfor byen. Denne endringen i den amerikanske posisjonen er resultatet av en lang rekke israelske seiere og gradvis amerikansk ettergivenhet. År for år er det lite endring å spore, men etter sytti år er endringene bemerkelsesverdige. Endringen kan ikke alene forklares med at Jerusalems status ble endret da Israel okkuperte 
hele byen i i967. Tendensen i utviklingen er den samme enten man behandler de to periodene hver for seg eller ser på dem som en kontinuitet.

\section{- $f \cdot$}

JøRGEN JENSEHAUgEn er førsteamanuensis i historie ved Høgskolen i Innlandet.

1 Peter L. Hahn, "Alignment by Coincidence: Israel, the United States and the Partition of Jerusalem," The International History Review 21, no. 3 (1999): 665-89; Elad Ben-Dror and Asaf Ziedler, "Israel, Jordan, and Their Efforts to Frustrate the United Nations Resolutions to Internationalise Jerusalem," Diplomacy \& Statecraft 26, no. 4 (2015): 636-58; Gadi Heimann, "The Struggle Between the United States and Israel over Recognition for Jerusalem as Israel's Capital, 1952-67," The International History Review 37, no. 4 (2015): 790-808; Arieh J. Kochavi, "Jerusalem in AngloAmerican Policy in the Immediate Wake of the June 1967 War," Israel Affairs 19, no. 3 (2013): 451-67.

2 Se for eksempel Donald Neff, Fallen Pillars: U.S. Policy Towards Palestine and Israel since 1945 (Washington D.C.: Institute for Palestine Studies, 2002); Shlomo Slonim, "The United States and the Status of Jerusalem: 1947-1984," Israel Law Review 19, no. 2 (1984): 179-252; Shlomo Slonim, Jerusalem in America's Foreign Policy, 1947-1997 (The Hague: Kluwer Law International, 1998); Yossi Feintuch, U.S. Policy on Jerusalem (New York: Greenwood Press, 1987); Selv Talhamis bok fra 2017 dekker bare opp til Clinton-perioden. Ghada Hashem Talhami, American Presidents and Jerusalem (Lanham, MD: Lexington Books, 2017).

3 Amir Tibon, "From Bill Clinton to Trump: The never-ending story of the Jerusalem embassy move", 5. februar 2017, Haaretz, haaretz.com/israel-news/.premium-1.769498?=\&ts= 1501573090506 (02.08.2017); Lior Lehrs, "Jerusalem on the Negotiating Table: Analyzing the Israeli-Palestinian Peace Talks on Jerusalem (1993-2015)," Israel Studies 21, no. 3 (2016): 179-205.

4 UN General Assembly Resolution 181, 29. november 1947, unispal.un.org/DPA/DPR/unispal.nsf/0/ 7F0AF2BD8976 89B785256C330061D253 (22.06.2017); Jørgen Jensehaugen, Marte Heian-Engdal, and Hilde Henriksen Waage,

"Securing the State: From Zionist Ideology to Israeli Statehood," Diplomacy \& Statecraft 23, no. 2 (2012): 28994; Folke Bernadotte, "Progress Report of the United Nations Mediator on Palestine Submitted to the Secretary-General for Transmission to the Members of the United Nations," September 16, 1948, content.ecf.org.il/files/ M00117_TheSecondBernadottePlan-EnglishText.pdf.

5 Jørgen Jensehaugen and Hilde Henriksen Waage, "Coercive Diplomacy: Israel, Transjordan and the UN - A Triangular Drama Revisited," British Journal of Middle Eastern Studies 39, no. 1 (2012): 82-83, 94-95.
6 Se for eksempel: "United States Representative at the UN to the Secretary of State, 11. november 1947”, Ruth Lapidoth and Moshe Hirsch, eds., The Jerusalem Question and Its Resolution: Selected Documents (Dordrecht: Martinus Nijhoff Publishers, 1994), 5.

7 Yossi Feintuch, U.S. Policy on Jerusalem (New York: Greenwood Press, 1987), 42.

8 Jerusalem to Foreign Office, 29. januar 1949, FO371/75347, Public Records Office, National Archives, Kew, London (PRO); Washington to Foreign Office, 1. mars 1949, FO371/75348, PRO; Candace Karp, Missed Opportunities: US Diplomatic Failures and the Arab-Israeli Conflict 1947-1967 (Claremont, CA: Regina Books, 2004), 97-122; Yossi Feintuch, U.S. Policy on Jerusalem, 19, 22, 40, 46-48.

9 Candace Karp, Missed Opportunities: US Diplomatic Failures and the Arab-Israeli Conflict 1947-1967, 122; Marte HeianEngdal, Jørgen Jensehaugen, and Hilde Henriksen Waage, “Finishing the Enterprise': Israel's Admission to the United Nations," The International History Review 35, no. 3 (2013): 477-78; Shlomo Slonim, "The United States and the Status of Jerusalem: 1947-1984,” 191.

10 Candace Karp, Missed Opportunities: US Diplomatic Failures and the Arab-Israeli Conflict 1947-1967, 124; The Consul at Jerusalem (Burdett) to the Secretary of State, 29. oktober 1949, FRUS: Foreign Policy of the United States, The Near East, South Asia and Africa, Vol. VI, 1949, vol. vi (Washington D.C: Department of State, United States Printing Office, 1977), 1456-1459; Elad Ben-Dror and Asaf Ziedler, "Israel, Jordan, and Their Efforts to Frustrate the United Nations Resolutions to Internationalise Jerusalem," 643; Peter L. Hahn, "Alignment by Coincidence: Israel, the United States and the Partition of Jerusalem," 669-70.

11 Elad Ben-Dror and Asaf Ziedler, "Israel, Jordan, and Their Efforts to Frustrate the United Nations Resolutions to Internationalise Jerusalem," 644; Donald Neff, Fallen Pillars: U.S. Policy Towards Palestine and Israel since 1945, 132, 13536; Heian-Engdal, Jensehaugen, and Waage, "Finishing the Enterprise," 475; Declaration of the Knesset regarding Jerusalem, 23 januar 1950, Ruth Lapidoth and Moshe Hirsch, The Jerusalem Question and Its Resolution, 105.

12 Donald Neff, Fallen Pillars: U.S. Policy Towards Palestine and Israel since 1945, 136; Peter L. Hahn, "Alignment by Coincidence: Israel, the United States and the Partition of Jerusalem," 670, 676-77; Shlomo Slonim, "The United States and the Status of Jerusalem: 1947-1984," 190-91, 198.

13 Gadi Heimann, "The Struggle Between the United States and Israel over Recognition for Jerusalem as Israel's Capital, 1952-67," 794-98; Donald Neff, Fallen Pillars: U.S. Policy Towards Palestine and Israel since 1945, 137; Yossi Feintuch, U.S. Policy on Jerusalem, 108-10; Statement made by the Secretary of State of the US, J.F. Dulles, concerning the removal of the Israeli Ministry for Foreign Affairs to Jerusalem, 28. juli 1953, Ruth Lapidoth and Moshe Hirsch, The Jerusalem Question and Its Resolution, 157. 
14 Gadi Heimann, "The Struggle Between the United States and Israel over Recognition for Jerusalem as Israel's Capital, 1952-67," 796-97; Yossi Feintuch, U.S. Policy on Jerusalem, 110-11.

15 Gadi Heimann, "The Struggle Between the United States and Israel over Recognition for Jerusalem as Israel's Capital, 1952-67," 800-801; Yossi Feintuch, U.S. Policy on Jerusalem, $116-18$

16 Statement made by US State Department concerning the retention of the American Embassy at Tel Aviv, 3. november 1954, Ruth Lapidoth and Moshe Hirsch, The Jerusalem Question and Its Resolution, 158; Gadi Heimann, "The Struggle Between the United States and Israel over Recognition for Jerusalem as Israel's Capital, 1952-67," 79495; Donald Neff, Fallen Pillars: U.S. Policy Towards Palestine and Israel since 1945, 137; Shlomo Slonim, "The United States and the Status of Jerusalem: 1947-1984,” 203.

17 Gadi Heimann, "The Struggle Between the United States and Israel over Recognition for Jerusalem as Israel's Capital, 1952-67," 799-801.

18 Shlomo Slonim, "The United States and the Status of Jerusalem: 1947-1984," 204-5.

19 Kathleen Christison, Perceptions of Palestine: TheirInfluence on U.S. Middle East Policy (London: University of California Press, 2001), 106-7.

20 Douglas Little, "The Making of a Special Relationship: The United States and Israel, 1957-68," International Journal of Middle East Studies 25, no. 4 (1993): 573.

21 Donald Neff, Fallen Pillars: U.S. Policy Towards Palestine and Israel since 1945, 137; Yossi Feintuch, U.S. Policy on Jerusalem, 120.

22 Elad Ben-Dror and Asaf Ziedler, "Israel, Jordan, and Their Efforts to Frustrate the United Nations Resolutions to Internationalise Jerusalem."

23 Peter L. Hahn, "Alignment by Coincidence: Israel, the United States and the Partition of Jerusalem," 688.

24 Avi Shlaim, The Iron Wall: Israel and the Arab World (New York: W.W. Norton, 2001), 244-45.

25 Nir Hasson, "Wary Israel Tried to Conceal East Jerusalem's Annexation in 1967, Documents Reveal”, Haaretz 18. april 2017, haaretz.com/israel-news/1.783429 (22.06.2017).

26 Nir Hasson, "Wary Israel Tried to Conceal East Jerusalem' Annexation in 1967, Documents Reveal", Haaretz 18. april 2017, haaretz.com/israel-news/1.783429 (22.06.2017); Shlomo Slonim, "The United States and the Status of Jerusalem: 1947-1984," 210-12; USA kom likevel med hard kritikk av denne administrative samlingen, se 'Statement by US Ambassador to the UN in the General Assembly concerning the measures taken by Israel with regard to East Jerusalem', 14. juli 1967, Ruth Lapidoth and Moshe Hirsch, The Jerusalem Question and Its Resolution, 174-77.
27 Lyndon B. Johnson, 'Address at the State Department's Foreign Policy Conference for Educators', 19. juni 1967, presidency.ucsb.edu/ws/ index.php?pid=28308 (22.06.2017); Donald Neff, Fallen Pillars: U.S. Policy Towards Palestine and Israel since 1945, 139.

28 UNSC Resolution 242, 22. november 1967, unispal.un.org/ DPA/DPR/unispal.nsf/0/7 D35E1F729DF491C85256 EE700686136 (30.06.2017)

29 Nigel Ashton, "Searching for a Just and Lasting Peace? Anglo-American Relations and the Road to United Nations Security Council Resolution 242," The International History Review 38, no. 1 (2016): 24-44; Arieh J. Kochavi, "Jerusalem in Anglo-American Policy in the Immediate Wake of the June 1967 War."

30 UNSC-resolusjon 252, 21. mai 1968, unispal.un.org/ DPA/DPR/unispal.nsf/0/46F2803D78A0488 E852560C3006023A8 (28.06.2017)

31 Shlomo Slonim, "The United States and the Status of Jerusalem: 1947-1984," 214.

32 UNSC-resolusjon 265, 1. april 1969, un.org/en/ga/ search/view_doc.asp?symbol=S/RES/267(1969) (28.06.2017); Ibid., 214-15.

33 'Statement by Ambassador Yost, of the US, in the Security Council, concerning the status of Jerusalem', 1. juli 1969, Ruth Lapidoth and Moshe Hirsch, The Jerusalem Question and Its Resolution, 236-38.

34 UN Security Council Resolution 298, 25. september 1971, unscr.com/en/resolutions/298 (22.06.2017).

35 UN Security Council Document S/12022, 24. mars 1976, theglobaleducationproject.org/mideast/ info/draftres.html\# 12022 (22.06.2017); Donald Neff, Fallen Pillars: U.S. Policy Towards Palestine and Israel since 1945, 143.

36 Ibid., 143-44.

37 For en full studie av Carters politikk i konflikten, se Jørgen Jensehaugen, "Part of the Problem, Not of the Solution: The Carter Administration and the Role of the Palestinians in the Arab-Israeli Conflict" (Unpublished PhD thesis, NTNU, 2016).

38 Lawrence Wright, Thirteen Days in September: Carter, Begin, and Sadat at Camp David (New York: Alfred A. Knopf, 2014), 256-60; Ezer Weizman, The Battle for Peace (New York: Bantam, 1981), 373; Moshe Dayan, Breakthrough: A Personal Account of the Egypt-Israel Peace Negotiations (New York: Random House, 1981), 177; William B. Quandt, Camp David: Peacemaking and Politics (Washington D.C.: Brookings Institution Press, 1986), 252; Zbigniew Brzezinski, Power and Principle: Memoirs of the National Security Adviser, 1977-1981 (New York: Farrar Straus \& Giroux, 1983), 270; Yaacov Bar-Siman-Tov, Israel and the Peace Process, $1977-$ 1982: In Search of Legitimacy for Peace (Albany: State University of New York Press, 1994), 128-29; Jimmy Carter, White House Diary (New York: Picador, 2010), 241-42; 
'Jimmy Carter to Anwar Sadat', 22. september 1978, Ruth Lapidoth and Moshe Hirsch, eds., The Jerusalem Question and Its Resolution: Selected Documents (Dordrecht: Martinus Nijhoff Publishers, 1994), 300.

39 UNSC-resolusjon 465, 1. mars 1980, unispal.un.org/DPA/ DPR/unispal.nsf/0/ 5AA254A1C8F8B1CB852560 E50075D7D5 (28.06.2017).

40 'Amembassy Tel Aviv to SecState WashDC', 5. mars 1980, Jimmy Carter Presidential Library [JCL], NLC-133-1-2-145; Terence Smith, "President Terms Anti-Israel Vote in U.N. an Error", 4. mars 1980, The New York Times; Carter, White House Diary, 406; 'Statement by the President of the US, Jimmy Carter, explaining the US vote for Security Council Resolution 465', 3. mars 1980, Ruth Lapidoth and Moshe Hirsch, The Jerusalem Question and Its Resolution, 313.

41 'Israel's Basic Law: Jerusalem, Capital of Israel', 30. juli 1980 (oversatt fra hebraisk), Ruth Lapidoth and Moshe Hirsch, The Jerusalem Question and Its Resolution, 322.

42 'Security Council Resolution 476 (1980)', 30. juni 1980, 'Israel's reaction' og 'U.S. statement', 1. juli 1980, Meron Medzini, ed., Israel's Foreign Relations Volume 6: 1979-80 (Jerusalem: Ministry of Foreign Affairs, 1984), 289-91.

43 Shlomo Slonim, "The United States and the Status of Jerusalem: 1947-1984,” Israel Law Review 19, no. 2 (1984): 241.

44 Se appendiks. Denne dataen er laget ved å sette sammen informasjon fra de følgende kildene: "Full Text of Draft Security Council Resolutions Relating To The IsraeliPalestinian Conflict Which One or More of the Five Permanent Security Council Members Voted Against", theglobaleducation project.org/mideast/info/draftres. html\#12022 (28.06.2017); United Nations Documents, undocs.org; Wikipedia.org, "List of UN Resolutions Concerning Israel and Palestine”, en.wikipedia.org/ wiki/ List_of_the_UN_resolutions_concerning_Israel_and_ Palestine\#United_Nations_Security_Council_resolutions (28.06.2017); Paul Lewis, "Mideast Diplomacy; U.N. Security Council Condemns the Hebron Slayings", 19. mars 1994, The New York Times, nytimes.com/1994/03/19/world/ mideast-diplomacy-un-security-council-condemns-thehebron-slayings.html (28.06.2017); UN Dag Hammarskjold Library, research.un.org/en/docs/sc/quick (29.06.2017).

45 Stephen Zunes, "U.S. Policy Toward Jerusalem: Clinton's shift to the right”, 1. juli 2000, Foreign Policy in Focus, fpif.org/ us_policy_toward_jerusalem_clintons_shift_to_the_right/ (03.08.2017)

46 William B. Quandt, Peace Process: American Diplomacy and the Arab-Israeli Conflict Since 1967 (Washington D.C.: Brookings Institution Press and the University of California Press, 2005), 74.

47 Saliba Sarsar, "The Question of Palestine and United States Behavior at the United Nations," International Journal of Politics, Culture, and Society 17, no. 3 (2004): 463-64.
48 Shlomo Slonim, Jerusalem in America's Foreign Policy, 19471997 (The Hague: Kluwer Law International, 1998), 310 (note 19), 331 (note 87).

49 Sarsar, "The Question of Palestine and United States Behavior at the United Nations," 460.

50 UKMis New York to FCO, 6. juli 1979, FCO 93/2176, PRO; Washington to FCO, 10. juli 1979, FCO 93/2176, PRO; UKMis New York to FCO, 11. juli 1979, FCO 93/2176, PRO; Beirut to FCO, 16. juli 1979, FCO 93/2057, PRO; Senior Level Meeting, 25. juli 1979, JCL, NLC-33-3-4-1-7; 'Summary of telephone conversation between Saunders and Dean', 27. juli 1979, JCL, NLC-131-1-2-19-3; 'Harold H. Saunders to The Secretary and Ambassador Strauss', 6. august 1979, JCL, NLC-126-17-42-1-6; The Situation Room to Susan Clough, 18. august 1979, JCL, NLC-128-421-3-9; 'The Situation Room to Prairie du Chien', 19. august 1979, JCL, NLC-128-4-21-2-0; 'The Situation Room to Susan Clough', 21. august 1979, JCL, NLC-128-4-21-1-1; SecState WashDC to US Mission USUN New York, 22. august 1979, JCL, NLC-16-117-6-8-1; 'W. R. Tomkys to D. Maitland', 23. januar 1980, FCO 93/2579, PRO.

51 Shlomo Slonim, "The United States and the Status of Jerusalem: 1947-1984,” 245-46; President Reagan's Peace Initiative, and accompanying talking points, 1 . september 1982, Ruth Lapidoth and Moshe Hirsch, The Jerusalem Question and Its Resolution, 364-71.

52 Donald Neff, Fallen Pillars: U.S. Policy Towards Palestine and Israel since 1945 (Washington D.C.: Institute for Palestine Studies, 2002), 145; Dokumenter fra debatten før avstemingen finnes i Ruth Lapidoth and Moshe Hirsch, The Jerusalem Question and Its Resolution, 377-427.

53 Donald Neff, Fallen Pillars: U.S. Policy Towards Palestine and Israel since 1945, 145; Phyllis Bennis, "The 2016 U.S. Presidential Campaign: Changing Discourse on Palestine," Journal of Palestine Studies, 34-49, 46, no. 1 (2016): 43.

54 Walid Khalidi, "Special Report: The Ownership of the Embassy Site in Jerusalem," Journal of Palestine Studies 24, no. 4 (2000): 82.

55 Donald Neff, Fallen Pillars: U.S. Policy Towards Palestine and Israel since 1945, 146; Walid Khalidi, "Special Report: The Ownership of the Embassy Site in Jerusalem," 82.

56 Walid Khalidi, "Special Report: The Ownership of the Embassy Site in Jerusalem"; Det amerikanske utenriksdepartementet mente at det ikke fantes noe bevis for dette. Se 'US Assistant Secretary of State for Legislative Affairs to Lee H. Hamilton, Chairman of the Subcommittee on Europe and the Middle East, US House of Representatives, concerning the leasing of property in Jerusalem for a US diplomatic mission', 29. juni 1989, Ruth Lapidoth and Moshe Hirsch, The Jerusalem Question and Its Resolution.; Raphael Ahren, «Jerusalem of Trump: Where the president-elect 
might put the US embassy», 13. desember 2016, Times of Israel, timesofisrael.com/jerusalem-oftrump-where-the-president-elect-might-put-the-usembassy/ (26.06.2017).

57 Donald Neff, Fallen Pillars: U.S. Policy Towards Palestine and Israel since 1945, 145.

58 Amir Tibon, "From Bill Clinton to Trump: The never-ending story of the Jerusalem embassy move", 5. februar 2017, Haaretz, haaretz.com/israelnews/.premium $-1.769498 ?=\& t s=\_1501573090506$ (02.08.2017).

59 Amir Tibon, "From Bill Clinton to Trump: The never-ending story of the Jerusalem embassy move", 5. februar 2017, Haaretz, haaretz.com/israelnews/.premium $-1.769498 ?=\&$ ts $=\_1501573090506$ (02.08.2017).

60 Waage, Peacemaking Is a Risky Business: Norway's Role in the Peace Process in the Middle East, 1993-96, 9293, 96, 99, 103, 116, 122, 130, 135, 137-39, 153.

61 Lior Lehrs, "Jerusalem on the Negotiating Table: Analyzing the Israeli-Palestinian Peace Talks on Jerusalem (1993-2015)," Israel Studies 21, no. 3 (2016): 179-80, 182-83.

62 John J. Mearsheimer and Stephen M. Walt, The Israel Lobby and U.S. Foreign Policy (New York: Farrar Straus Giroux, 2007), 127; Walid Khalidi, "Special Report: The Ownership of the Embassy Site in Jerusalem," 83; US Congress, "Jerusalem Embassy Act of 1995," 1995, congress.gov/104/plaws/publ45/ PLAW-104pub145.pdf (26.06.2017).

63 Patrick Goodenough, “State Dept.: Moving Embassy to Jerusalem Could 'Needlessly' Put Diplomats, Troops 'in Harm's Way", 5. januar 2017, CNSNews, cnsnews.com/news/article/patrick-goodenough/statedept-moving-embassy-jerusalem-could-needlesslyput-diplomats (27.06.2017).

64 Peter Baker, «Donald Trump Won’t Move Embassy to Jerusalem, at Least for Now», 1. juni 2017, The New York Times, nytimes.com/2017/06/01/world/ middleeast/israel-embassy-jerusalem-trump.html (26.06.2017); Patrick Goodenough, "State Dept.: Moving Embassy to Jerusalem Could 'Needlessly' Put Diplomats, Troops 'in Harm's Way"', 5. januar 2017, CNSNews, cnsnews.com/news/article/patrickgoodenough/state-dept-moving-embassy-jerusalemcould-needlessly-put-diplomats (27.06.2017).

65 Michael Zank, "The Jerusalem Basic Law (1980) and the Jerusalem Embassy Act (1995): A Comparative Investigation of Israeli and US Legislation on the Status of Jerusalem," Israel Studies 21, no. 3 (2016): 23.

66 Lior Lehrs, "Jerusalem on the Negotiating Table," 198; Ian S. Lustick, "Yerushalayim, Al-Quds and the
Wizard of Oz: Facing the Problem of Jerusalem after Camp David II and the Al-Aqsa Intifada," The Journal of Israeli History 23, no. 2 (2004): 213.

67 Patrick Goodenough, "State Dept.: Moving Embassy to Jerusalem Could 'Needlessly' Put Diplomats, Troops 'in Harm's Way”, 5. januar 2017, CNSNews, cnsnews.com/news/article/patrick-goodenough/statedept-moving-embassy-jerusalem-could-needlesslyput-diplomats (27.06.2017)

68 Rick Gladstone, "Buoyed by Donald Trump Win, Jerusalem Mayor Hopes to Get U.S. Embassy”, 11. desember 2016, The New York Times, nytimes.com/ 2016/12/11/world/middleeast/buoyed-by-donaldtrump-win-jerusalem-mayor-hopes-to-get-usembassy.html? smid=tw-nytimesworld\&smtyp $=$ cur \&_r=0 (27.06.2017); Adam Liptak, "Supreme Court Backs White House on Jerusalem Passport Dispute", 8. juni 2015, The New York Times, nytimes.com/ 2015/06/09/us/politics/supreme-court-backs-whitehouse-on-jerusalem-passport-dispute.html (27.06.2017).

69 Adam Liptak, "Supreme Court Backs White House on Jerusalem Passport Dispute", 8. juni 2015, The New York Times, nytimes.com/2015/06/09/us/ politics/supreme-court-backs-white-house-onjerusalem-passport-dispute.html (27.06.2017).

70 UNSC-resolusjon 2334, 23. desember 2016, un.org/webcast/pdfs/SRES2334-2016.pdf (28.06.2017).

71 Barack Obama, "Remarks in Cairo, 4. juni 2009, The American Presidency Project, presidency.ucsb.edu/ ws/print.php?pid=86221 (29.06.2017).

72 Ethan Bronner og Mark Landler, "Israel Offers a Pause in Building New Settlements», 25. november 2009, The New York Times, nytimes.com/2009/ 11/26/world/middleeast/26israel.html (29.06.2017); Asaf Siniver, "Change Nobody Believes In: Obama and the Israeli-Palestinian Conflict," Diplomacy \& Statecraft 22, no. 4 (2011): 685.

73 Lior Lehrs, "Jerusalem on the Negotiating Table," 183.

74 Siniver, “Change Nobody Believes In,” 688

75 Data om Øst-Jerusalems bosetterbefolkning utarbeidet av Daniel Seidemann, oversendt forfatteren per epost 30.06.2017. Hovedbolken av dataen er basert på Jerusalem Statistical Yearbook, jiis.org.il.

76 Stephen Zunes, "U.S. Policy Toward Jerusalem: Clinton's Shift to the right", 1. juli 2000, Foreign Policy in Focus, fpif.org/us_policy_toward_ jerusalem_clintons_shift_to_the_right/ (03.08.2017).

77 Shlomo Slonim, Jerusalem in America's Foreign Policy, 1947-1997, 284-97. 
78 Raphael Ahren, «Jerusalem of Trump: Where the president-elect might put the US embassy», 13 . desember 2016, Times of Israel, timesofisrael.com/jerusalem-of-trump-where-thepresident-elect-might-put-the-us-embassy/ (26.06.2017); “Erekat: 'Hope of peace will vanish' if US moves embassy to Jerusalem”, 20. desember 2016, Maan news, maannews.com/Content. aspx?id=774517 (26.06.2017); Barak Ravid, "Moving U.S. Embassy to Jerusalem 'Very Big Priority' for Trump, Senior Advisor Says", 12. desember 2016, Haaretz, haaretz.com/israel-news/1.758560 (26.06.2017).

79 Raphael Ahren, «Jerusalem of Trump: Where the president-elect might put the US embassy», 13. desember 2016, Times of Israel, timesofisrael.com/jerusalem-of-trump-where-thepresident-elect-might-put-the-us-embassy/ (26.06.2017)

80 Patrick Goodenough, "State Dept.: Moving Embassy to Jerusalem Could 'Needlessly' Put Diplomats, Troops 'in Harm's Way"', 5. januar 2017, CNSNews, cnsnews.com/news/article/patrick-goodenough/statedept-moving-embassy-jerusalem-could-needlesslyput-diplomats (27.06.2017)

81 «Erekat: Moving US Embassy to Jerusalem will 'destroy peace process"', 15. desember 2016, Times of Israel, timesofisrael.com/erekat-moving-us-embassyto-jerusalem-will-destroy-peace-process/ (26.06.2017); Barak Ravid, "Abbas doesn't expect Trump will move U.S. embassy to Jerusalem, threatens response if he does", 3. januar 2017, Haaretz, haaretz.com/israel-news/.premium1.762870 (26.06.2017).

82 Josh Lederman, "Tillerson: Trump weighing whether embassy move will help or hurt peace”, 14. mai 2017, Times of Israel, timesofisrael.com/tillerson-trumpweighing-whether-embassy-move-will-help-or-hurtpeace/ (27.06.2017).

83 Vivian Salama og Josef Federman, «Trump administration flip flops on location of Western Wall», 22. mai 2017, Chicago Tribune, chicagotribune.com/news/ nationworld/politics/ct-trump-western-wall20170522-story.html (30.06.2017).

84 Vivian Salama og Josef Federman, «Trump administration flip flops on location of Western Wall», 22. mai 2017, Chicago Tribune, chicagotribune.com/news/ nationworld/politics/ct-trump-western-wall20170522-story.html (30.06.2017); Amir Tibon, “Trump's Secretary of State Refuses to Say Western Wall Is in Israel”, 22. mai 2017, Haaretz, haaretz.com/israel-news/1.790922 (30.06.2017).

85 Siniver, "Change Nobody Believes In," 684.

86 Anne Gearan, «Trump policy on Israel is evolving in somewhat surprising way», 3. februar 2017,
Washington Post, washingtonpost.com/world/ national-security/trump-policy-on-israel-is-evolvingin-somewhat-surprising-ways/2017/02/03/6d61b9eaea4b-11e6-80c2-30e57e57e05d_story.html?utm term $=$. ac75b50218d2 (30.06.2017)

87 Shlomo Slonim, Jerusalem in America's Foreign Policy, 1947-1997, 267, 276-77. 